\title{
WAVE HEIGHTS RECOVERY FROM SUBSURFACE PRESSURES UPON A SMALL VERTICAL CYLINDER
}

\author{
Tri Cao Mai ${ }^{1}$, Torsten Schlurmann ${ }^{2}$
}

\section{INTRODUCTION}

There are various techniques used to observe waves at sea. These techniques can be divided into two main techniques. The first one is in-situ technique in which instruments are deployed in the water such as wave buoys wave poles, inverted echo-sounders, pressure transducers and curren meters. The second is remote-sensing technique, in which instruments are deployed at some distance above the water surface such as imaging techniques and altimetry.

The pressure transducer, one of the in-situ techniques, is used in this study Traditionally, a pressure transducer can measure wave-induced pressure fluctuations at various depths below the water surface. These fluctuations, in combination with the linear wave theory (Airy theory), can be used to estimate wave characteristics. There have been many studies on application of this technique in estimation of wave parameters [1, 2, 3, 4, 5\& 9].

In this study, under water pressures upon a small vertical cylinder are measured. These pressure records, in combination with the first-order diffraction theory [6, 7 \& 8], can be used to derive water surface wave heights. Therefore, this research focuses on further study on estimation of wave heights from subsurface pressures upon a small vertical cylinder.

\section{EXPERIMENT}

A scale 1:12 physical model was constructed in the large wave flume (GWK) in Hannover, Germany to experiment waves attacking on a tripod structure as well as scour development around the structure. The tests were performed with a water depth of 2.5 meters at the location of the tripod structure. The wave attacks, under sea state condition of the significant wave height $H_{s}=0.66$ $\mathrm{m}$ and the peak wave period $T_{p}=5.52 \mathrm{~s}$, were measured by using seven pressure sensors mounted on the surface of the structure (see Figure 1). The sampling rate of the experiment is $100 \mathrm{~Hz}$

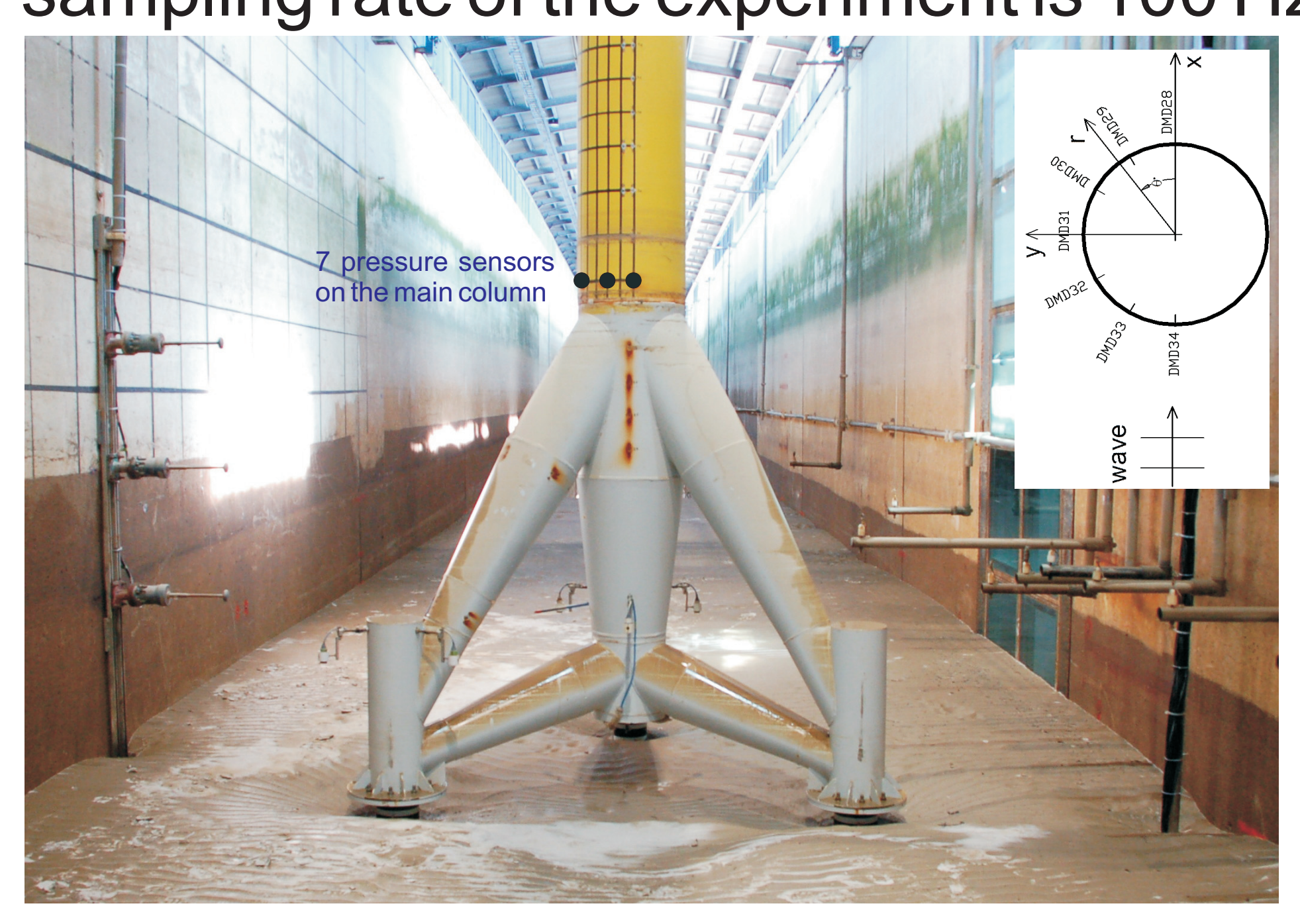

Figure 1: The tripod in the large wave flume (GWK).

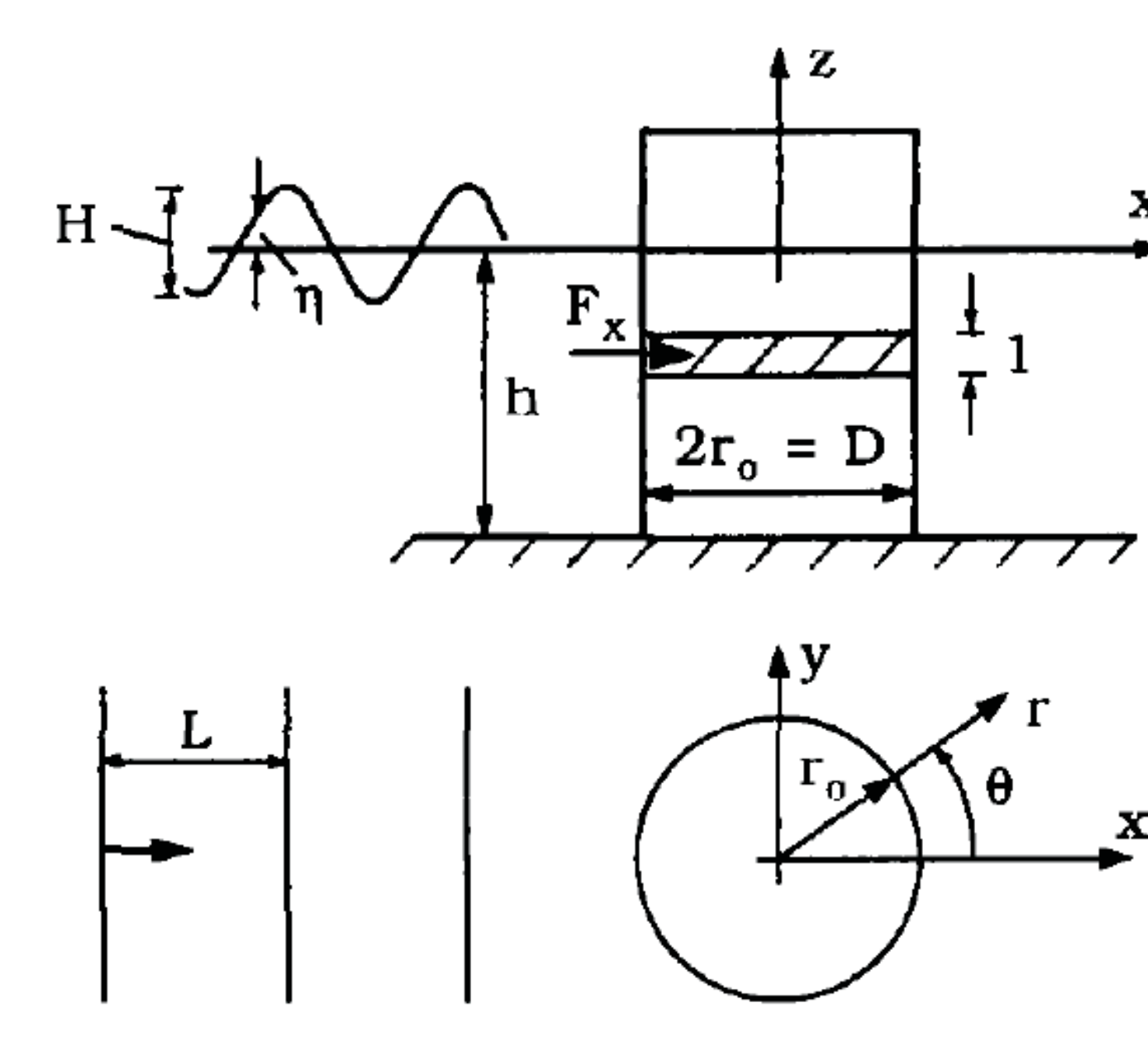

Figure 2: Definition sketch for a vertical circular cylinder (Sumer et al., 2006).

\section{THEORETICALASPECT}

From the linear feature of potential flow, the total potential function, $\phi$, can be written as the sum of two potential functions: $\phi=\phi_{i}+\phi_{\mathrm{s}}$, in which, $\phi_{\mathrm{i}}$ is the potential function of the undisturbed incident wave and $\phi_{\mathrm{s}}$ is the potential function of the scattered (reflected and diffracted) wave. In the case of smal cylinder (i.e. $D / L<0.2, D$ is the cylinder diameter and $L$ is the wave length), only the potential function of the undisturbed incident wave is considered: $\phi=\phi_{i}$ Therefore, according to MacCamy \& Fuchs $[6,7 \& 8]$ the dynamic pressure exerts on the surface of the cylinder can be expressed as a function of time $t$ frequency $f$, submerge level $z$ and the angle $\theta$ of orientation of the point on the surface of the cylinder w.r.t the incident wave direction (see Figure 2).

$$
p(t, f, z, \theta)=\frac{\rho g H}{2} \frac{\cosh k(h+z)}{\cosh (k h)} \cdot\left[J_{0}\left(k r_{0}\right)+\sum_{p=1}^{\infty} 2 i^{p} J_{p}\left(k r_{0}\right) \cos (p \theta)\right] \cdot e^{-i \theta t}
$$

Transferfunction: $\quad T F(f, z, \theta)=\operatorname{real}\left\{\frac{\cosh k(d+z)}{\cosh (k d)} \cdot\left[J_{0}\left(k r_{0}\right)+\sum_{p=1}^{\infty} 2 i^{p} J_{p}\left(k r_{0}\right) \cos (p \theta)\right]\right\}$

Estimated surface spectrum: $\quad S_{\eta \eta}^{p}(f, z, \theta)=|\rho \cdot g \cdot T F(f, z, \theta)|^{-2} S_{p p}(f, z, \theta)$

Empirical factor:

$$
N(f, z, \theta)=\sqrt{\frac{S_{\eta \eta}^{m}(f)}{S_{\eta \eta}^{p}(f, z, \theta)}}
$$

\section{SUMMARY OF RESULTS}

The empirical factors for all pressure records with respect to wave gauge WP13 and WP14 are presented in Figure 3. Eq. 4 is applied to estimate these empirical factors from the measured waves and their concurrent pressure data. Overview from two bottom plots of Figure 3 shows that the empirical factors of DMD 33 \& 34 range from 0.9 to 1.1 in frequency range of $0.13 \mathrm{~Hz}$ to $0.4 \mathrm{~Hz}\left(0.75^{\star} f_{\text {peak }}\right.$ to $\left.2.18^{\star} f_{\text {peak }}\right)$ and the others are much higher than 1.1 .
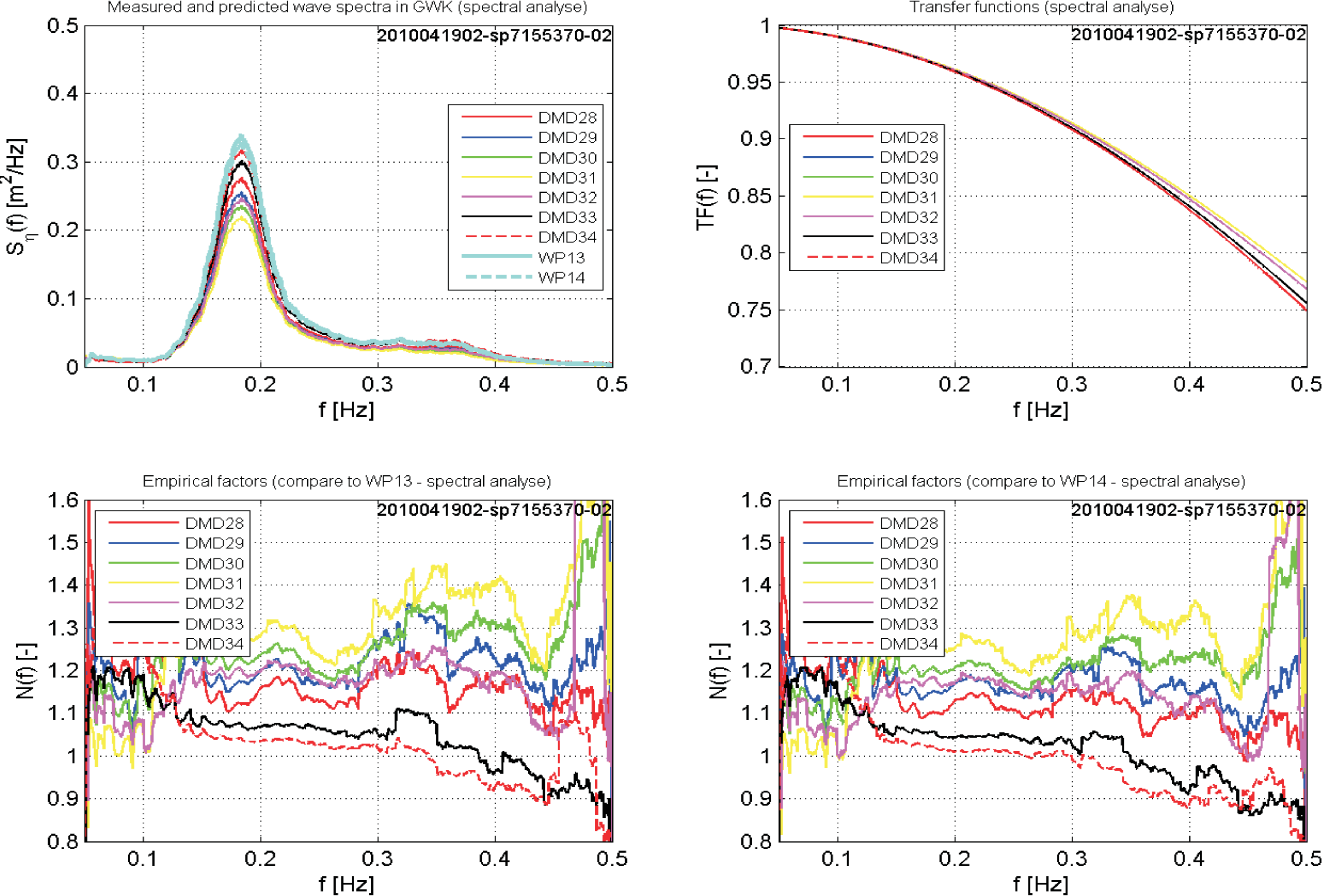

Figure 3: Spectral densities of water surface; transfer function TF and Empirical factor $N$.

The measured and predicted wave spectral densities are shown in the top left plot of Figure 3 and it shows that the predicted wave spectrum from DMD34 fits quite well to the measured wave spectrum of the wave gauge WP14 which measured wave heights synchronously next to the structure.

Additionally, the ratio of the predicted significant wave height $\left(H_{s}^{p}\right)$ and the measured significant wave height $\left(H_{s}^{m}\right)$ is presented for all tests in Figure 4.

The significant wave heights estimated from sensor DMD34 $\left(\theta=180^{\circ}\right)$ are the best agreement with the measured values of WP14 and have the ratio of $H_{s}^{p} / H_{s}^{m}$ almost equals 1 . The values estimated from DMD33 $\left(\theta=150^{\circ}\right)$ have also good agreement to the measured values $\left(H_{s}^{p} / H_{s}^{m}=0.97\right.$ to 1.01). For the other sensors (at $\theta=0^{\circ}$ to $120^{\circ}$ ) the estimated significant wave heights are much lower than the measured values in which the ratio $H_{s}^{p} / H_{s}^{m}$ ranges from 0.85 to 0.95 .

\section{ACKNOWLEDGMENTS}

The authors gratefully acknowledge the support of the German Federa Environment Ministry (BMU) within the funded project "Ganzheitliches Dimensionierungskonzept für OWEATragstrukturen hinsichtlich Lasten Langlebigkeit, Gründung und Gesamtstruktur (GIGAWIND alpha ventus LUH)" (BMU code 0325032/A). Project details and cooperation partners can be collected from www.gigawind.de.

\section{REFERENCES}

[1] Bishop, C.T. and Donelan, M.A., "Measuring waves with pressure transducers". Coastal Engineering 11, 309-328 (1987). [3] Escher, J. and Schlurmann, T., "On the recovery of the free surface from the pressure within periodic traveling water waves". Journal of Nonlinear Mathematical Physics, V5-2, 50-57 (2008).

(2) [5] Kuo, Y. Y. and Chiu, Y. . ., "Transfer function between the wave height and wave pressure for progressive waves". Coastal Engineering 23,

[6] MacCamy, R.C. and Fuchs, R.A., "Wave forces on piles: a diffraction theory". U.S. Army Corps of Engineering, Beach Erosion Board Washington, D.C., Tech M, R.A., Wave forces

B. M., Fredsøe, J., "Hydrodynamics around cylindrical structures” (Revised Edition). World Scientific Publishing Co. Pte. Ltd Denmark (2006).
[8] Sundar, V., Neelamani, S. And Vendhan, C.P., "Dynamic pressures on a large vertical cylinder due to random waves". Coastal Engineering 13,83-104 (1989).
[9] Tsai, C.H., Huang, M... Young, F.J., Lin, Y.C. and Li, H.W., "On the recovery of surface wave by pressure transfer function". Ocean 